\title{
Molecular Inclusion -Novel Approach to Enhance Solubility of Olmesartan Medoxomil using Hydroxypropyl $\beta$ cyclodextrin (HP $\beta$-CD)
}

\author{
Swati S. Gaikwad ${ }^{1 *}$, Jasmine G. Avari² \\ 1 Nagpur college of Pharmacy, Wanadongri, Hingna road, Nagpur \\ 2 Department of Pharmaceutical Sciences, R. T. M. Nagpur University, Nagpur, India
}

\begin{abstract}
Olmesartan medoxomil (OLM) is a BCS Class II anti-hypertensive drug, which is having low aqueous solubility and low bioavailability of $26 \%$. In the present study, the objective of the study was to improve the pharmaceutical limitation of OLM by using Molecular Inclusion Technique. Inclusion complex of OLM with Hydroxypropyl $\beta$ cyclodextrin (HP $\beta$-CD) were prepared in drug/carrier molar ratios of 1:1, 1:2, and 1:3 by Solvent evaporation and Kneading method along with the Physical mixtures. The formation of molecular inclusion complex at 1:2 ratio in the solution was confirmed by Job's Plot study. The inclusion complex were characterized by Phase solubility study, Fourier transform infrared spectroscopy, Scanning electron microscopy, Differential scanning calorimetry and X-ray diffraction studies. In-vivo pharmacokinetic study reveals enhanced bioavailability of inclusion complexes. Thus, it can be concluded that the formulation of molecular inclusion complex can enhance Solubility and Dissolution making the drug more suitable for treatment.
\end{abstract}

Keywords: Olmesartan medoxomil, Molecular Inclusion, Stability Constant, Dissolution, HP $\beta$-CD.

\section{INTRODUCTION}

In recent trends, there are many of newly synthesized active agents that suffer from low aqueous solubility and dissolution and therefore have low bioavailability. There are two approaches that focus on improving the oral bioavailability that

\footnotetext{
${ }^{*}$ Corresponding Author: Ms. Swati Sanjay Gaikwad

E-mail: swati.gaikwad05@gmail.com ORCID: https://orcid.org/0000-0002-7896-063X

Nagpur college of Pharmacy, Wanadongri, Hingna road, Nagpur, India.

Tel.: +91-7709493400;

ORCIDs

Swati Gaikwad: 0000-0002-7896-063X

Jasmine Avari: 0000-0002-5213-5092

(Received 02 November 2019, accepted 10 September 2020)
} 
is enhancement of solubility and dissolution rate and increasing permeability of such drugs. Solubilisation, salt formation, complexation, solid dispersion and size reduction are commonly used approaches to increase dissolution rate. Amongst all these, solid dispersion technology is the promising approach for improvement of solubility and dissolution rate of poorly water soluble drugs ${ }^{1}$. Recently, Solid dispersion technology was explored extensively for the delivery of the drugs having poor solubility. Solid dispersions are mixtures in which drugs exist either in an amorphous form dispersed in the carrier molecule or included into the cavity of the carrier molecule ${ }^{2}$. Molecular inclusion technology has been proved a promising form of drug delivery. It offers dispersion or inclusion of a hydrophobic drug in a hydrophilic matrix of a carrier molecule in order to improve the dissolution rate which eventually improves the bioavailability of the drug.

Cyclodextrin (CD) inclusion complexation has been proved as a promising technique in enhancing solubility of insoluble drugs. There is the formation of hostguest inclusion complexes by weak intermolecular interaction ${ }^{3}$. The structure of cyclodextrin appears as a truncated cone, which has hydrophilic exterior surface and a lipophilic interior cavity into which drug molecules get entrapped ${ }^{4}$. Hydroxypropyl- $\beta C D$ (HP $\beta C D$ ) is the commonly used excipients in several pharmaceutical formulations 5 . From the literature survey it was revealed that the solubility of $\beta C D$ in water is relatively low (approximately $18.5 \mathrm{mg} / \mathrm{mL}$ at 25 ${ }^{\circ} \mathrm{C}$ ), as compared to its derivative HP $\beta C D$ which has a higher aqueous solubility (approx. $600 \mathrm{mg} / \mathrm{mL}$ at $25{ }^{\circ} \mathrm{C}$ ). The reason behind the higher solubility of $\mathrm{HP} \beta C D$ is the chemical modification in the $\beta \mathrm{CD}$ by the addition of hydroxy propylene oxide group ${ }^{6}$. Also, HP- $\beta$ cyclodextrin is most useful drug complexing agent because of its ability to readily form complexes and reasonable cost. Therefore, it was thought worthwhile to select $\mathrm{HP} \beta C D$ as a carrier for the formation of molecular inclusion complex.

Olmesartan medoxomil is a specific angiotensin II type I antagonist used alone or with other anti-hypertensive agents to treat hypertension. Olmesartan has poor aqueous solubility and low bioavailability of $26 \%$. In the recent study, it was also explored that OLM has a better renal protective effect than other Angiotensin receptor blockers. Therefore, improvement of solubility of OLM can prove this drug as a better option for the treatment of Hypertension for the patients suffering from renal disorder ${ }^{3}$. HP- $\beta \mathrm{CD}$ forms inclusion complexes in both solid and solution state, which can lead to modification in physical as well as chemical properties of the guest molecule. Solid drugs can be complexed with HP- $\beta C D$ by using solvent evaporation, freeze drying, kneading, roll mixing etc. techniques. 
The objective of the present study is to develop OLM-molecular inclusion complex with improved solubility using Hydroxypropyl- $\beta$ cyclodextrin (HP $\beta C D$ ) as a carrier with various techniques like physical mixing, solvent evaporation and kneading. The study includes phase solubility study, characterization of inclusion complex by DSC and, SEM, determination of stability constant of the complex, solubilisation and stability studies of the product.

\section{METHODOLOGY}

\section{Materials}

Olmesartan medoxomil (Mylan Laboratories, Hyderabad), HP- $\beta$ Cyclodextrin (Kleptose ${ }^{\circledR}$ Roquette, France) and other reagents used were of AR Grade.

\section{Preparation of Inclusion Complexes}

1) Physical mixtures: The physical mixtures of Drug OLM and HP- $\beta$ Cyclodextrin in different ratios were prepared by mixing the pulverised powders and passing them through \#100 mesh sieve

2) Kneading: The Drug and HP- $\beta$ Cyclodextrin were triturated in different ratios using sufficient amount of water to form a thick paste, which was further kneaded for 15 minutes. Then it was allowed to dry in a hot air oven. The dried mass was then triturated using mortar and pestle, sieved through \#100 mesh sieve, stored in a desiccator.

3) Solvent evaporation: To a drug solution in 70\% v/v of Ethanol (10 ml) appropriate amount of HP- $\beta$ Cyclodextrin, in different ratios were added. This solution was allowed to stir continuously using hot plate magnetic stirrer until the solvent evaporated. Solid dispersion thus obtained was then pulverized, sieved through mesh 100, stored in a desiccator.

\section{Characterization of Drug, Excipients and Solid Dispersion}

\section{Fourier transform infra-red spectroscopy (IR)}

To study and confirm any drug-excipients interaction, Fourier Transform Infrared (FTIR) spectroscopy was performed. Initial spectra of the drug (OLM) and HP- $\beta C D$ as control along with the solid dispersions were recorded. About 5-10 mg of test samples was used to study FTIR. FTIR spectroscopy of the test samples were performed by using the $\mathrm{KBr}$ scanning over wave number range of 4000-400 $\mathrm{cm}^{-1}$ with FTIR spectrophotometer (FTIR-8001, Shimadzu, Japan) operated with IR Solution Software.

Drug (OLM), HP- $\beta$ CD, physical mixture and Solid Dispersion were filled in amber colored vials sealed with bromo butyl rubber stoppers and kept in the 
environmental stability chamber (Remi Lab, Mumbai, India) for accelerated stability condition at $40 \pm 2^{\circ} \mathrm{C}$ temperature and $75 \pm 5 \%$ relative humidity for a period of 30 days. FTIR spectra of samples were obtained and spectra of solid dispersions were compared with the initial spectra of drug and excipients.

\section{Differential Scanning Calorimetry (DSC)}

DSC curves of OLM, HP- $\beta$ Cyclodextrin, physical mixture and solid dispersion prepared by kneading method and solvent evaporation were obtained by using DSC (SHIMADZU DSC 60 PLUS, Japan) at a heating rate of $5{ }^{\circ} \mathrm{C} / \mathrm{min}$ from 30 ${ }^{\circ} \mathrm{C}$ to $300{ }^{\circ} \mathrm{C}$ in a nitrogen atmosphere. DSC curves of samples were obtained, and spectra of solid dispersions compared with the initial spectra of drug and excipients to confirm the formation of inclusion complex.

\section{X-Ray Diffractometry (XRD)}

$\mathrm{XRD}$ was carried out at room temperature using a D/max 2500VL/PC powder $\mathrm{X}$-ray diffractometer (Rigaku, Japan) was operated at $40 \mathrm{kV}$ and $35 \mathrm{~mA}$ to analyse the physical nature of the drug and inclusion complexes. Test samples were scanned over a $2 \theta$ range of $3-40$ with a step size of $0.020^{\circ}$ and a step time of $59.7 \mathrm{~s}$.

\section{Scanning electron microscopy}

The SEM images of OLM, HP- $\beta$ Cyclodextrin and inclusion complexes prepared was observed by scanning electron microscope (JSM- 5510 (Jeol Ltd. Tokyo, Japan) with the accelerating voltage $10-\mathrm{kV}$ and current of $25 \mathrm{~mA}$. In this technique, the test samples were placed in the metal stub having two way adhesive tape and under reduced pressure of about 2.54 pa; it was coated with the very fine platinum film. The SEM images obtained were observed and analysed at different scale or resolutions.

\section{Determination of stability constant of the complex}

\section{Phase solubility studies}

Higuchi and Connors method is a classical method for the Solubility studies, thus used here to perform phase solubility studies. In this method, excess drug was added to $30 \mathrm{ml}$ of distilled water containing different molar concentrations of HP- $\beta$ cyclodextrin (0.002-0.01 M). These mixtures were shaken on the orbital shakers at 250 revolution per minute for $24 \mathrm{hrs}$ at the room temperature. The samples were then removed from shaker and allowed to achieve equilibrium. The aliquots were then filtered through wattman filter paper. The samples were suitably diluted and analysed using UV spectrophotometer by measuring the absorbance at $254 \mathrm{~nm}$ wavelength. 


\section{Spectrophotometric studies}

Complex formation between OLM and HP- $\beta$ cyclodextrin was studied by keeping the OLM concentration fixed as $2.445 \times 10-8 \mathrm{M}$ whereas the concentration of HP- $\beta$ cyclodextrin was increased from 0.002 to $0.01 \mathrm{M}$. The spectra of the drug were recorded on a UV-Vis spectrophotometer, Shimadzu (UV-180o $240 \mathrm{~V}$, Japan). The change in the absorbance of drug on the addition of various concentration of the HP- $\beta$ cyclodextrin were measured at $254 \mathrm{~nm}$ to evaluate the stability constant of the complex. A stability constant is a measure of the strength of the interaction which represent the equilibrium constant for the formation of a complex in solution.

Similarly, the UV spectra of the OLM, physical mixtures and inclusion complexes prepared by solvent evaporation and kneading method in different ratios were recorded and overlayed. The absorbance values of each sample containing fixed concentration of drug were measured at $254 \mathrm{~nm}$ to evaluate the enhanced solubility.

\section{Dissolution and Accelerated Stability studies}

\section{In vitro dissolution studies}

In vitro dissolution studies of pure drug, inclusion complexes and innovator (marketed product) were performed using LABINDIA DS 8000 USP paddle method at $50 \mathrm{rpm}$ in $900 \mathrm{ml}$ of $0.1 \mathrm{~N} \mathrm{HCl}$ acid $(\mathrm{pH} 1.2)$ as dissolution media. The temperature was maintained at $37 \pm 0.5^{\circ} \mathrm{C} .5 \mathrm{ml}$ sample was withdrawn at the time intervals of $5,10,15,30,40$ and 50 minutes, filtered through wattmann filter paper and analyzed spectrophotometrically at $254 \mathrm{~nm}$. After each withdrawal of the sample an equal volume of prewarmed fresh medium at the same condition, was replaced into the dissolution media to maintain the constant volume throughout the test ${ }^{9}$.

\section{Accelerated stability testing}

Inclusion complexes were kept in sealed amber coloured bottles, protected from light and stored at $40^{\circ} \mathrm{C} / 75 \% \mathrm{RH}$ for 6 months. The products were analyzed for FTIR spectroscopy, drug content and dissolution after 6 month.

\section{RESULTS and DISCUSSION}

\section{Physical characterization}

\section{FT-IR Spectroscopy:}

The FT-IR spectra of pure Olmesartan medoxomil shows characteristic peaks at 2929.87, (C-H, str), 1707, 1739.79, 1830.45 (C-O, str) and $3288.63 \mathrm{~cm}-1$ (N-H, 
str) The spectra of molecular inclusion complex of Olmesartan medoxomil with HP- $\beta$ cyclodextrin showed (Fig. 1) The characteristic peaks of Olmesartan medoxomil at initial conditions was maintained indicating that there is no chemical interaction between drug and excipients. Also, it was observed that there were no changes in the physical appearance of the samples.

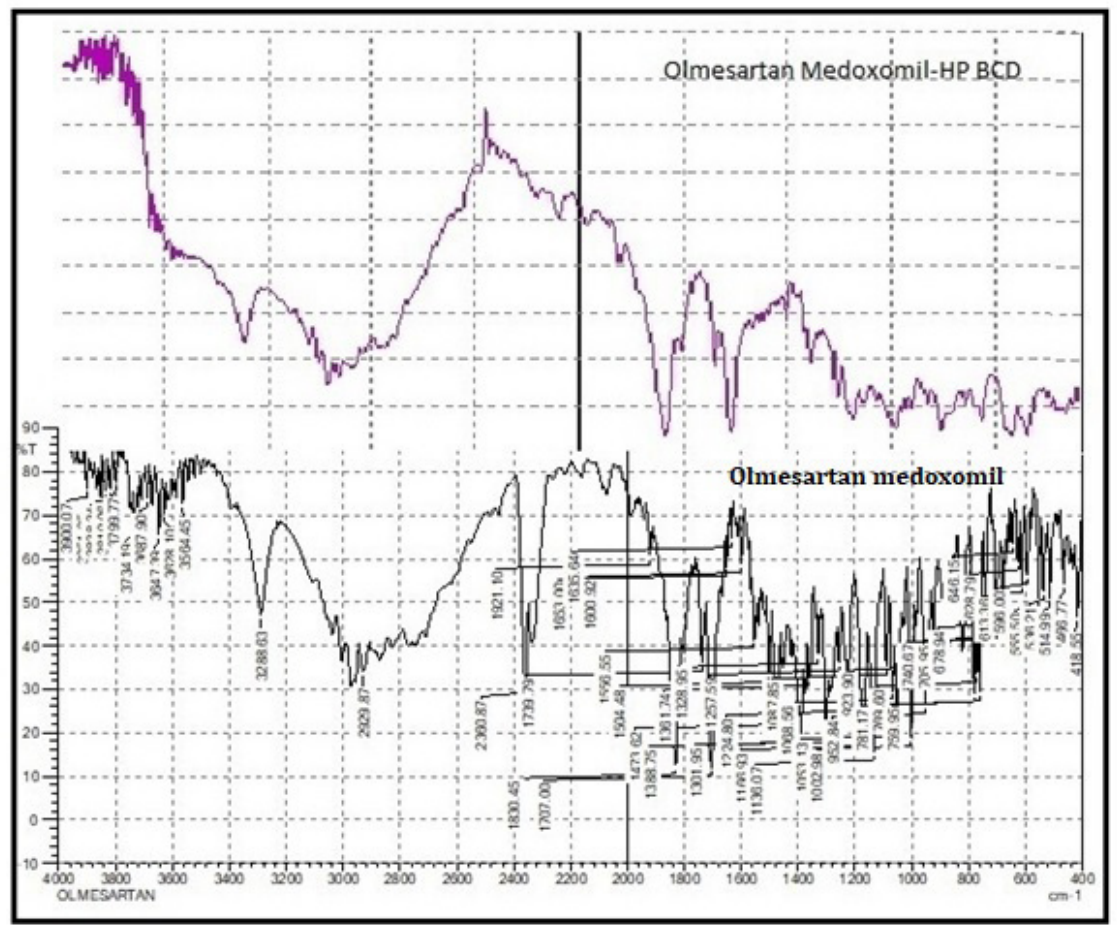

Figure 1. FTIR spectra of Pure Olmesartan Medoxomil (OLM) and complex of Hydroxypropyl $\beta$ cyclodextrin (HP $\beta C D$ ) and Olmesartan Medoxomil (OLM).

\section{DSC studies}

The DSC thermograms of Olmesartan medoxomil, HP- $\beta$ cyclodextrin and the inclusion complexes are shown in Fig. 2. The DSC curve of HP- $\beta$ cyclodextrin shows a broad endothermic peak which was due to its amorphous nature. The sharp peak of Olmesartan medoxomil appeared at $184.02{ }^{\circ} \mathrm{C}$, whereas no such peak was observed in inclusion complex prepared with HP- $\beta$ cyclodextrin suggesting that Olmesartan was molecularly dispersed. It might have been no longer available in a crystalline state, and was converted into the amorphous state. 


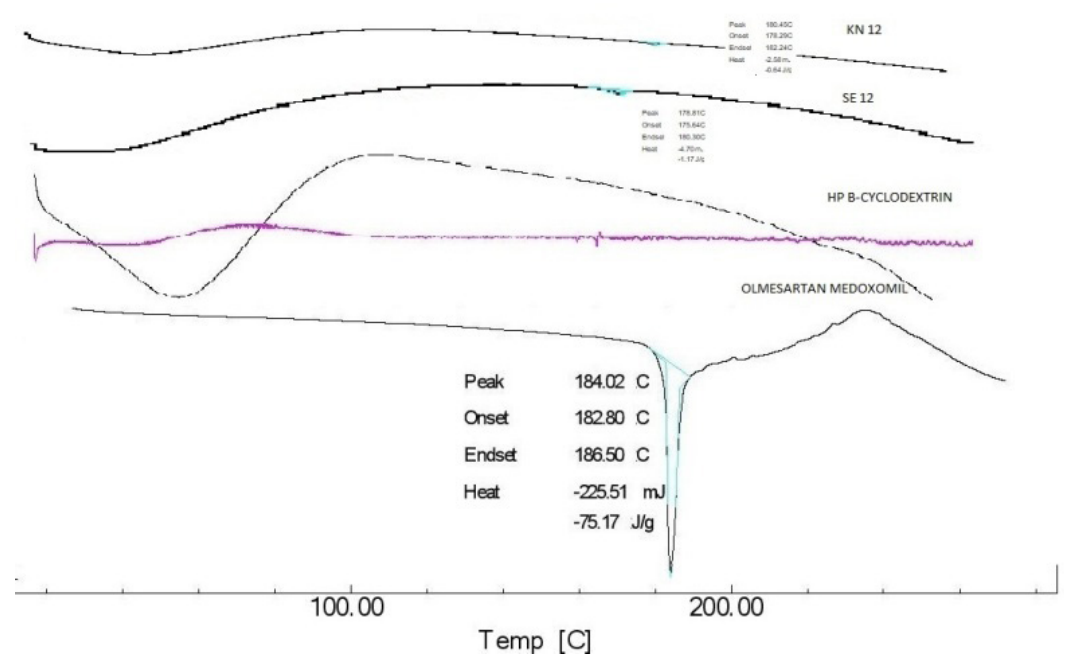

Figure 2. DSC curves of Pure OImesartan Medoxomil (OLM), Hydroxypropyl $\beta$ cyclodextrin (HP $\beta C D$ ), Olmesartan Medoxomil (OLM): Hydroxypropyl $\beta$ cyclodextrin (HP $\beta C D$ ) kneaded complex (1:2), and Olmesartan Medoxomil (OLM): Hydroxypropyl $\beta$ cyclodextrin (HP $\beta C D$ ) solvent evaporated complex (1:2).

\section{SEM ANALYSIS}

The surface morphological features of OLM, HP- $\beta C D$, and inclusion complexes are shown in figure 3 . The complexes appeared as agglomerates rather than individual crystalline structures. This change of the particle shape was indicative of a conversion of solid crystalline state to amorphous state of the complexes.
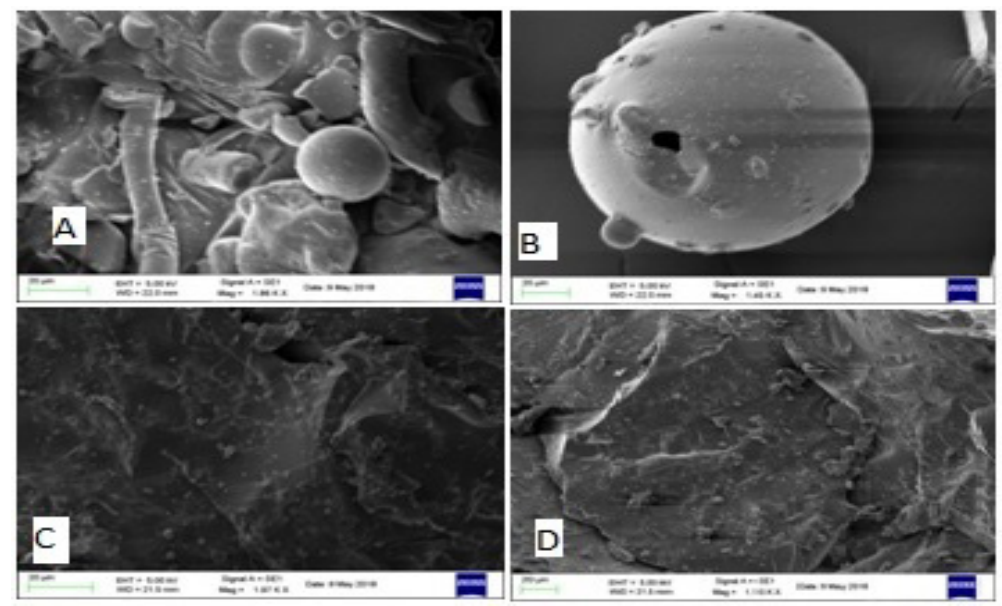

Figure 3. Scanning electron microscopic images of A- OLM and HP- $\beta$ CD, B- HP- $\beta$ CD, C -Inclusion complex of HP $\beta$-CD (SE 12) and D- Inclusion complex of HP $\beta$-CD (KN 12) 


\section{XRD analysis}

The crystallinity of the pure drug and inclusion complexes could be studied through XRD patterns as shown in the fig 4. It was observed that pure OLM exhibited a characteristic peaks in the $2 ø$ angle located at $7^{\circ}, 9^{\circ}, 11^{\circ}, 12^{\circ}, 14^{\circ}, 16$ ${ }^{\circ}, 19^{\circ}$, and $21^{\circ}$ which indicates the crystalline nature of OLM. Whereas, X-ray diffractometer graph of HP- $\beta C D$ shows no characteristic peak, which indicates the amorphous nature of the carrier. When the inclusion complex prepared by solvent evaporation and kneading technique were analysed, they also showed completely diffused diffraction patterns indicating conversion of crystalline form into amorphous. This suggests that OLM was entrapped within the hydrophobic cavity of $\mathrm{HP} \beta \mathrm{CD}$. Absence of crystallinity and developed amorphous nature of the evaporated and kneaded complexes of OLM: HP $\beta C D$ suggests the improved solubility and dissolution profile of OLM in gastrointestinal media.

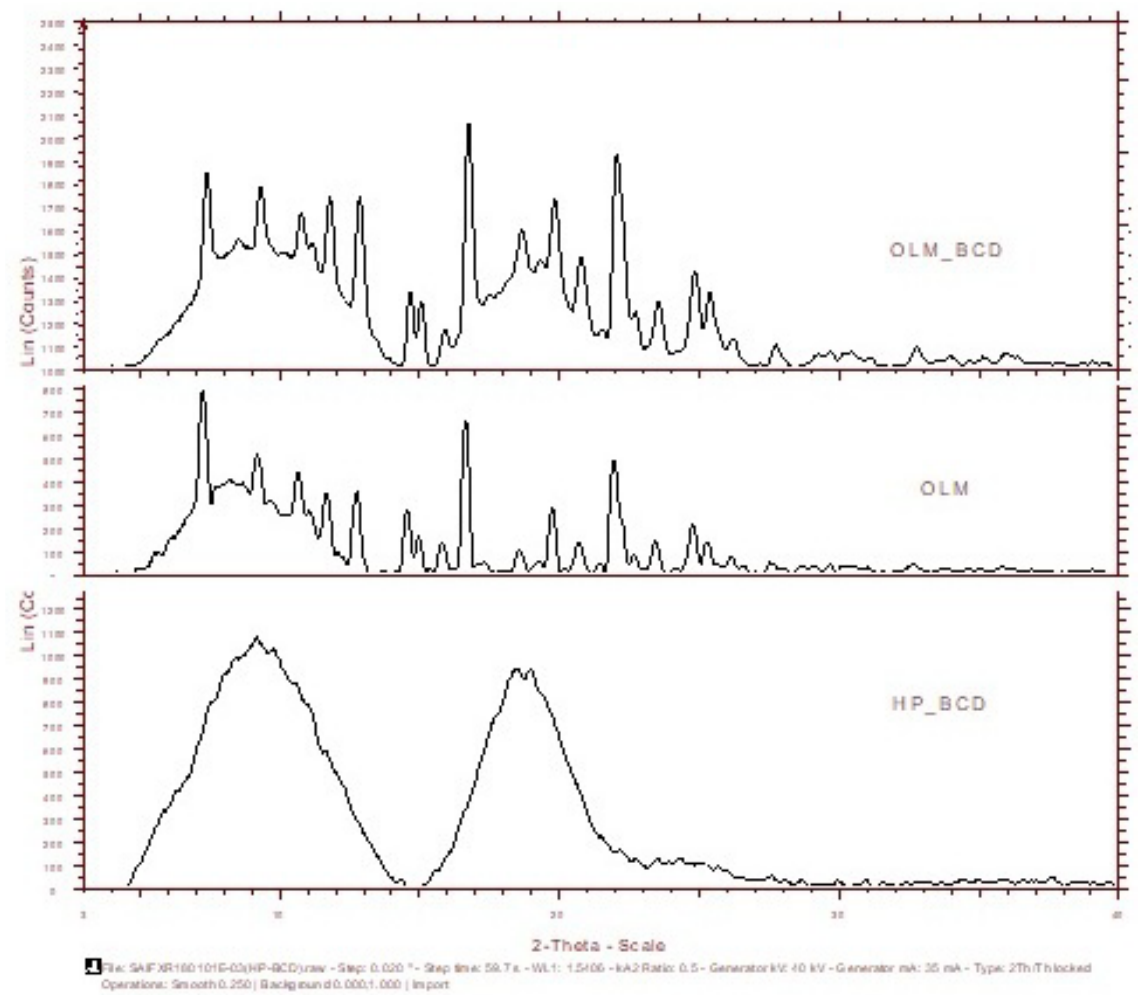

Figure 4. X-ray diffraction patterns of Pure Olmesartan Medoxomil (OLM), Hydroxypropyl $\beta$ cyclodextrin (HP $\beta C D$ ) and kneading complex of Hydroxypropyl $\beta$ cyclodextrin (HP $\beta C D)$ and Olmesartan Medoxomil (OLM) 


\section{UV Spectroscopy}

The Olmesartan medoxomil solution in the presence of increasing molar concentration of HP- $\beta C D$ was scanned and analysed on UV spectrophotometer. The spectra of each solution recorded are shown in Fig. 5. There are changes observed in the peak intensity in-spite of addition of fixed amount of drug in solution. This may be the result of transfer of the drug molecule from water to the HP- $\beta C D$ cavity, resulting in enhanced solubility of drug as indicated by the increased peak intensity ${ }^{10}$.

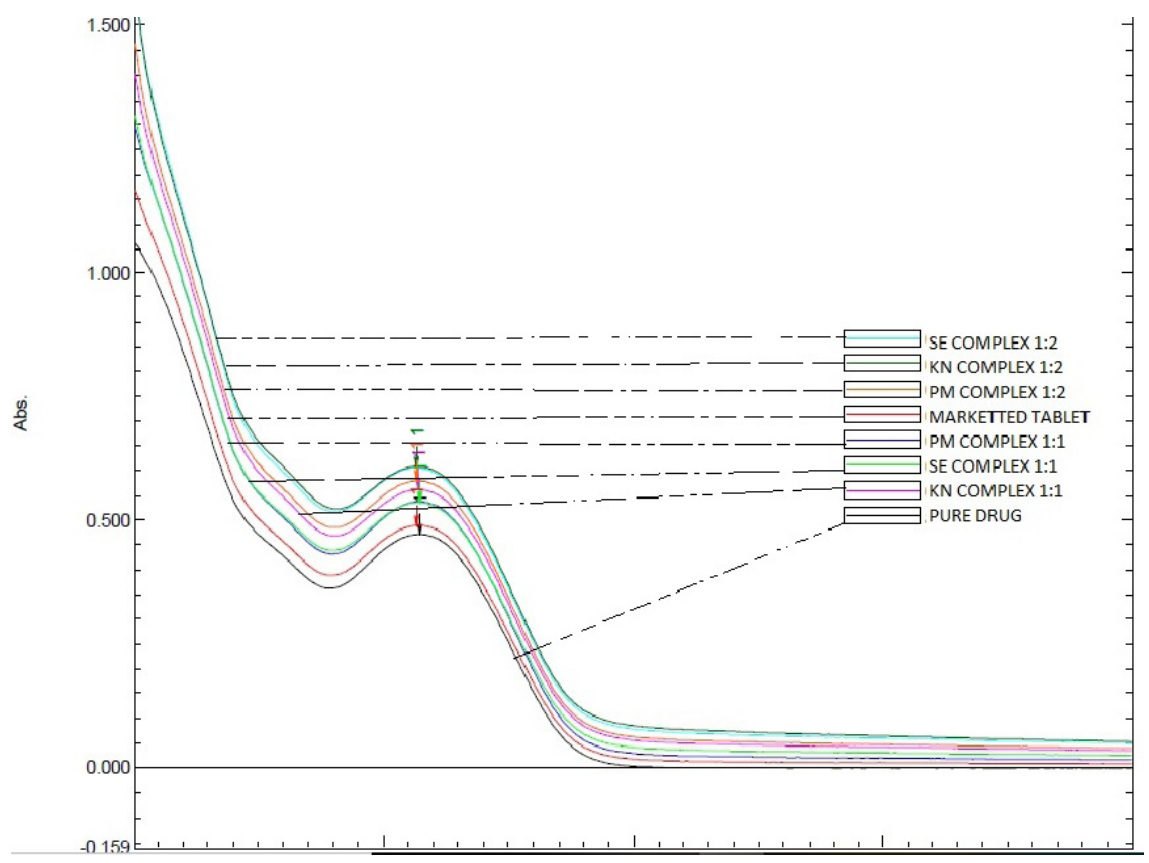

Figure 5. Overlay Spectra of Olmesartan Medoxomil (OLM) and various complexes prepared with Hydroxypropyl- $\beta$ cyclodextrin (HP $\beta C D$ ).

\section{Determination of Stability Constants}

The complexing behaviour of Olmesartan Medoxomil with the HP- $\beta$ cyclodextrin was studied by the phase-solubility method. The phase solubility diagram for the inclusion complex formation between Olmesartan medoxomil and HP- $\beta$ cyclodextrin is shown in Fig. 6. It was observed from the phase solubility diagram that the aqueous solubility of Olmesartan medoxomil have increased linearly, as a function of HP- $\beta$ cyclodextrin concentration. The graph shows the value with a slope $0.1957(\mathrm{r}=0.9643)$. The stability constant $(\mathrm{Kc})$ of Olmesartan medoxomil was calculated as $11858.15 \mathrm{M}^{-1}$ from the plot of the phase solubility diagram and using the equation 


$$
\boldsymbol{K c}=\frac{\text { Slope }}{\text { So(1-Slope) }} \text { (1) }
$$

where, So is the solubility of drug. It can be concluded from the results obtained by using method of continuous variation (Job's Plot) as shown in fig.7 that the increase in solubility observed was due to the formation of a 1:2 M inclusion complex.

\section{PHASE SOLUBILITY}

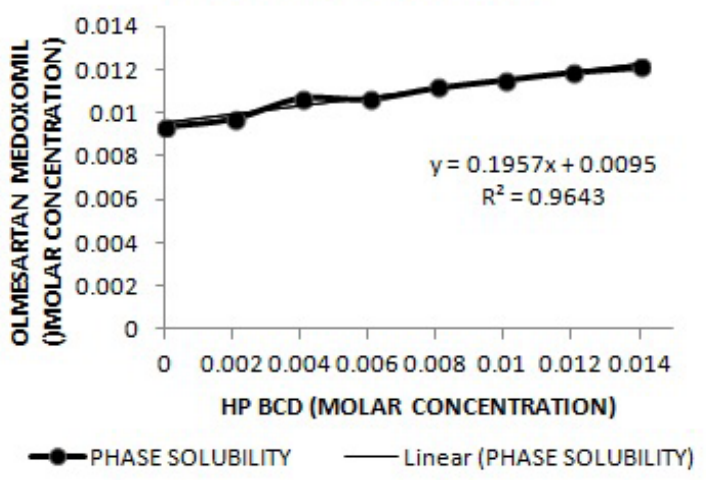

Figure 6. Phase solubility diagram of Olmesartan Medoxomil (OLM) in Hydroxypropyl $\beta$ cyclodextrin (HP $\beta C D)$ solution.

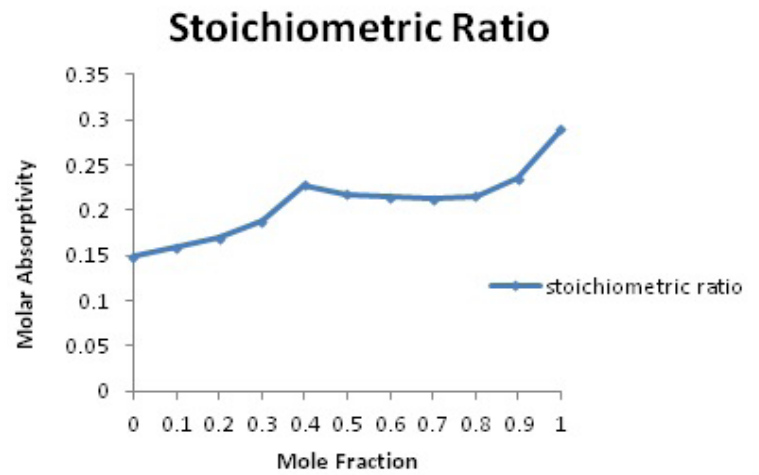

Figure 7. Job's Plot showing stoichiometric ratio of Olmesartan Medoxomil (OLM) in Hydroxypropyl $\beta$ cyclodextrin (HP $\beta C D$ ) molecular inclusion complex. 
Absorption spectra used to confirm the formation of inclusion complex and to compare the degree of enhancement of solubility. In this study, absorption spectra of HP- $\beta$ cyclodextrin, Olmesartan medoxomil, physical mixture and inclusion complex were taken into consideration. In the absorption spectra for Olmesartan medoxomil and the physical mixture there is only a slight increase in the absorbance peak along the wavelength was recorded which may be due to the higher wetting effect of the available HP- $\beta$ cyclodextrin with drug. Whereas, inclusion complex showed much more rise in intensity at all points of wavelength, this may be due to the inclusion or molecular dispersion of drug in HP- $\beta$ cyclodextrin cavity.

Stability constant was determined using the Benesi-Hildebrand equation

$$
\frac{1}{\Delta A}=\frac{1}{(\mathrm{D})} \boldsymbol{K c} \Delta € X \frac{1}{(\mathrm{CD})}+\frac{1}{\text { (D) }} \Delta € \quad 2
$$

where $\Delta \mathrm{A}$ is the difference of absorbance at $254 \mathrm{~nm},(\mathrm{CD})$ the HP- $\beta$ cyclodextrin concentration, (D) the drug concentration (constant), and $\Delta €$ is the difference in the molar absorptivity values between the complex and the free drug. The Kc value was calculated to be $5531.12 \mathrm{M}^{-1}$. It was found that the stability constant which was calculated by a spectral shift technique was relatively small compared to that obtained by the phase solubility studies. However, from the literature chaudhary et.al it was noted that the use of the spectral shift technique is not the method of choice for a reliable determination the drug with low aqueous solubility, because the difference in the absorptivity values will be too small $^{11}$. In contrast, the other phase solubility method provides a much better and reliable results in these cases $^{12}$.

\section{In vitro dissolution studies}

The dissolution curves of Pure drug, Physical mixtures, Solvent evaporation and Kneading solid dispersions in $0.1 \mathrm{~N} \mathrm{HCl}(\mathrm{pH}=1.2)$ at $37 \pm 0.5^{\circ} \mathrm{C}$ are shown in Fig. 8 and the corresponding values are given in Table 2. From the results obtained, it was observed that all the binary systems of Olmesartan Medoxomil demonstrated higher dissolution rates than pure drug and its corresponding physical mixtures. The physical mixtures also showed improved dissolution rate as compared with OLM but the highest drug release is observed for molecular inclusion complexes prepared by Kneading method. It is evident that the inclusion complex improved the dissolution rate of OLM to the greatest extent. Amongst all preparations, OLM: HP- $\beta C D$ 1:2 inclusion complex produced by kneading method showed highest dissolution rate of about $96.73 \%$ of drug in $\mathrm{pH} 1.2$ at the end of $30 \mathrm{~min}$. 


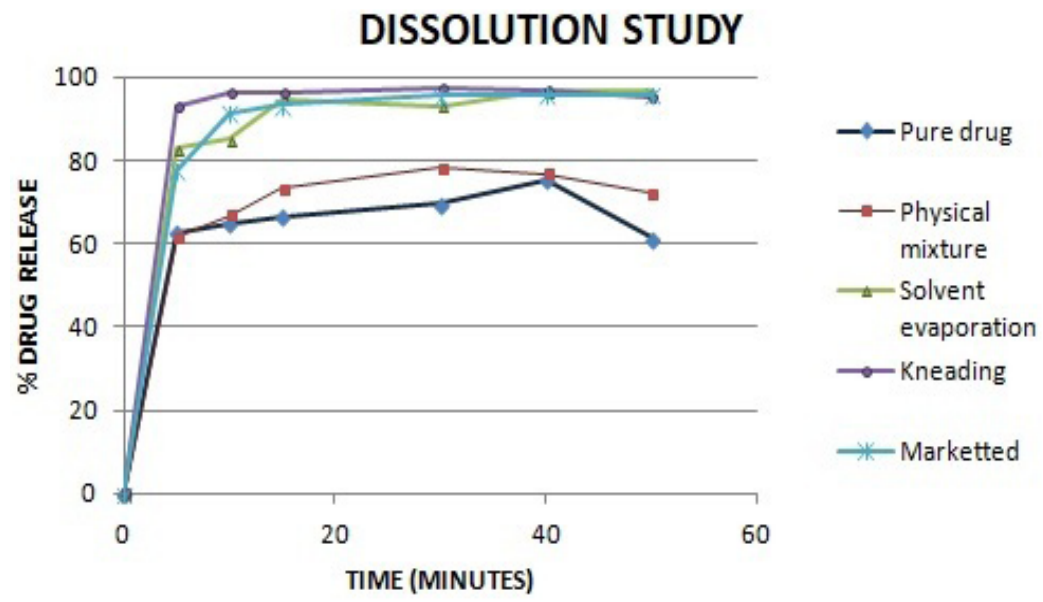

Figure 8. Dissolution profile of Olmesartan Medoxomil, prepared Olmesartan Medoxomil (OLM) : Hydroxypropyl $\beta$ cyclodextrin (HP $\beta C D$ ) molecular inclusion complexes and Marketed preparation in $0.1 \mathrm{~N}$ hydrochloric acid.

Table 1. Olmesartan medoxomil content in HP $\beta C D$ inclusion complex systems prepared.

\begin{tabular}{|c|c|c|c|}
\hline Method & Formulation code & Complex system & $\begin{array}{l}\text { Olmesartan medoxomil } \\
\text { content }(\%)\end{array}$ \\
\hline \multirow{3}{*}{$\begin{array}{l}\text { Physical } \\
\text { mixing }\end{array}$} & PM 11 & Olmesartan medoxomil: HP- $\beta C D(1: 1)$ & 98.52 \\
\hline & PM 12 & Olmesartan medoxomil: HP- $\beta C D(1: 2)$ & 98.64 \\
\hline & PM 13 & Olmesartan medoxomil: HP- $\beta C D(1: 3)$ & 98.45 \\
\hline \multirow{3}{*}{ Kneading } & KN 11 & Olmesartan medoxomil: HP- $\beta C D(1: 1)$ & 99.21 \\
\hline & KN 12 & Olmesartan medoxomil: HP- $\beta C D(1: 2)$ & 99.10 \\
\hline & KN 13 & Olmesartan medoxomil: HP- $\beta C D(1: 3)$ & 98.78 \\
\hline \multirow{3}{*}{$\begin{array}{c}\text { Solvent } \\
\text { evaporation }\end{array}$} & SE 11 & Olmesartan medoxomil: HP- $\beta C D(1: 1)$ & 98.11 \\
\hline & SE 12 & Olmesartan medoxomil: HP- $\beta C D(1: 2)$ & 98.24 \\
\hline & SE 13 & Olmesartan medoxomil: HP- $\beta C D(1: 3)$ & 98.37 \\
\hline \multicolumn{4}{|c|}{$\begin{array}{l}\text { PM 11; Physical Mixture (1:1), PM 12; Physical Mixture (1:2), PM 13; Physical Mixture (1:3), KN 12; Kneading } \\
\text { Complex (1:1),KN 12; Kneading Complex (1:2), KN 13; Kneading Complex (1:3), SE 11; Solvent Evaporation } \\
\text { Complex (1:1) ,SE 12; Solvent Evaporation Complex (1:2), SE 13; Solvent Evaporation Complex (1:3). }\end{array}$} \\
\hline
\end{tabular}


Table 2. Dissolution profile of Olmesartan medoxomil in $0.1 \mathrm{~N}$ hydrochloric acid

\begin{tabular}{|c|c|c|c|c|c|}
\hline \multirow{2}{*}{ TIME (min) } & \multicolumn{5}{|c|}{ Mean percentage of drug dissolved $(\mathbf{\pm S D})^{*} \mathbf{n}=\mathbf{3}$} \\
\cline { 2 - 6 } & PD & PM 12 & SE12 & KN 12 & INN \\
\hline $\mathbf{5}$ & $62.52(1.56)$ & $61.69(1.01)$ & $82.86(1.19)$ & $92.88(0.59)$ & $77.56(1.14)$ \\
\hline $\mathbf{1 0}$ & $64.66(1.75)$ & $66.88(1.14)$ & $85.25(1.63)$ & $96.46(1.53)$ & $91.47(1.01)$ \\
\hline $\mathbf{1 5}$ & $66.27(1.68)$ & $73.32(1.11)$ & $94.73(0.73)$ & $96.29(1.01)$ & $93.32(1.01)$ \\
\hline $\mathbf{3 0}$ & $69.52(0.83)$ & $78.08(1.20)$ & $93.08(1.40)$ & $97.40(1.17)$ & $95.54(1.5)$ \\
\hline $\mathbf{4 0}$ & $75.09(1.63)$ & $76.86(1.23)$ & $96.61(1.15)$ & $96.73(0.97)$ & $95.79(0.74)$ \\
\hline $\mathbf{5 0}$ & $61.18(1.00)$ & $71.92(2.14)$ & $96.51(1.00)$ & $95.09(1.57)$ & $95.84(1.37)$ \\
\hline $\mathbf{D E}_{\mathbf{1 5}} \%$ & 59.66 & 61.75 & 77.23 & 83.52 & 77.79 \\
\hline Similarity factor & 36.94 & 42.01 & 78.37 & 65.59 & Reference \\
\hline
\end{tabular}

PD, Pure Drug; PM 12; Physical Mixture (1:2), SE 12; Solvent Evaporation Complex (1:2), KN 12; Kneading Complex (1:2), INN, Marketed Tablet (Powdered)

Dissolution efficiency (\% DE) is the area under the dissolution curve between time point's $t_{1}$ and $t_{2}$ expressed as a percentage of the curve at maximum dissolution, y100, over the same time period and is expressed by the following expression:

Dissolution efficiency $(D E)=\frac{\int_{t 1}^{t 2} y d t}{y 100(t 2-t 1)}$

$\mathrm{DE}_{15} \%$ values of PD, PM12, SE12, KN12 and INN are found to be 59.66, $61.75,77.23,83.52$ and 77.79 respectively.

\section{Accelerated stability testing:}

Accelerated stability testing results showed no significant variations neither in the content of drug nor in dissolution profiles after storage at $40^{\circ} \mathrm{C} / 75 \% \mathrm{RH}$ for 6 months. Therefore, all these results imply that the prepared molecular inclusions are stable over the storage period and no effect on its stability on storage.

In the present study it was clearly observed that OLM immediate release inclusion complex can be effectively produced by processing via HP- $\beta C D$ with enhanced solubility and Dissolution Rate. The results of the studies also indicated the formation of HP $\beta$ CD- Olmesartan medoxomil molecular inclusion complex prepared by kneading method at different ratios of drug and HP- $\beta C D$. The inclusion complex had enhanced dissolution rate of OLM to a greater extent compared to the corresponding solvent evaporation, physical mixture and pure OLM. Further, it was noted that OLM-incorporated molecular inclusions in 1:2 ratio aqueous solution provides the highest dissolution and solubility 
values compared to the marketed product and OLM pure drug, which indicate that the oral bioavailability of OLM might be improved. Kneading method was the most effective method in terms of OLM solubility and dissolution. This enhanced dissolution from the inclusion complexes may be the result of increased hydrophilicity and wetting effect that results from the interaction between the drug and the carrier ${ }^{13,14}$. The another reason for the rapid dissolution of OLM from inclusion complexes may be attributed to the entrapment of drug in the hydrophilic carrier matrix of carrier HP- $\beta C D$ and a decrease in the crystallinity of drug as observed in XRD and DSC studies. Further, in the mechanism of quick dissolution of drug from the inclusion complexes could be due to the soluble carrier dissolving into the dissolution medium and allowing the entrapped drug release to the medium in the form of very fine particles.

Thus, we can conclude that HP- $\beta C D$ is useful as a primary carrier in the formulation of molecular inclusion complex of the drug (OLM) prepared by kneading method so as to enhance its solubility and dissolution rate.

\section{ACKNOWLEDGEMENT}

The authors are thankful to Mylan Lab. Pvt. Ltd., Hyderabad, India, for providing the gift sample of drug and Rouquette, France for providing gift sample of KLEPTOSE ${ }^{\circledR} \mathrm{HP}-\beta \mathrm{CD}$ for this research.

We are thankful to BARTI, Pune, Babasaheb Ambedkar National Research Fellowship-2014 for providing a fellowship. 


\section{REFERENCES}

1. Aggarwal, S.; Gupta G.D.; Chaudhary S. Solubility and dissolution enhancement of poorly aqueous soluble drug. Int. J. of Drug Deliv. 2012, 4, 341-365.

2. Kalepua, S.; Nekkant, V. Insoluble drug delivery strategies: review. Acta Pharmaceut.Sin. B. $2015,5 \cdot 5,442-453$.

3. Takashi, O.; Oru, S.;Yoshito, M.; Ritsuya N. Olmesartan is More effective than other Angiotensin receptor antagonist in reducing proteinuria in patients with chronic kidney disease other than Diabetic Nephropathy. Cur.Therap.Res. 2013, 74,63-67.

4. Loftsson, T.; Brewster, M.E. Pharmaceutical applications of cyclodextrins 1. Drug solubilisation and stabilization. J Pharm Sci 1996, 85, 1017-1025.

5. Singh, R.; Bharti, N.; Madan, J. et al. Characterization of cyclodextrin inclusion complexes - a review. J Pharm Sci Technol. 2010, 2, 171-183.

6. Gabriel, O.K.L.; Yvonne, T.F.T.; Kok-Khiang, P.Enhancement of norfloxacin solubility via inclusion complexation with $\beta$-cyclodextrin and its derivative hydroxypropyl- $\beta$-cyclodextrin. Asian J. of Pharma. Scien. II. 2016, 536-546.

7. Li, N.Inclusion complex of trimethoprim with $\beta$-cyclodextrin. J. Pharmaceut. Biomed. 2005 $39,824-829$.

8. Sean, C.S. Martindale, The Complete Drug Reference. 36th Edition. Pharmaceutical Press, 2009.

9. Dehghan, M.H.G.; Jafar M. Improving dissolution of meloxicam using solid dispersions. Iranian J Pharm Res., 2006, 4, 231-238.

10. Ismail, S. Interaction of anticonvulsant drugs with alpha and beta-cyclodextrins. I. Methsumide. STP Pharm. Sci. 1991, 321-325.

11. 10. Shah, T.J.; Amin, A.F.; Parikh, J.R. Process optimizationand characterization of poloxamer solid dispersions of a poorly water soluble drugs. AAPS Pharm Sci Tech. 2007, 8.2, E1E7.

12b Chaudhary, K.P.R.; and Nalluri, B.N.; Studies on nimesulide and bcyclodextrin inclusion complexes. physicochemical characterization and dissolution rate studies. Drug Dev Ind Pharm. 2000;26:1217-1220

13. Yang, L.J.; Chen, W.; Ma, S.X. et al. Host-guest system of taxifolin and native cyclodextrin or its derivative: preparation characterization, inclusion mode, and solubilization. Carbohydr Polym. 2011, 85, 629-637.

14. Yuvaraja, K.; Khanam, J. Enhancement of carvedilol solubility by solid dispersion technique using cyclodextrins, water soluble polymers and hydroxyl acid. J. of Pharmac. and Biomed. Anal. 2014, 96, 10-20. 